\title{
Rivadeneyra en Dizful Notas sobre un óleo dedicado a la aventura española en Oriente ${ }^{1}$
}

\author{
Rivadeneyra in Dizful. \\ Notes about an oil painting dedicated to the Spanish \\ adventure in the Near East
}

JOAQUÍN MARÍA CÓRDOBA²

\begin{abstract}
RESUMEN
En el curso del siglo XIX, numerosos europeos emprendieron viajes por Oriente Próximo e Irán. Muchos dejaron recuerdo de éstos en libros relevantes, que describían ruinas, costumbres y paisajes.

Uno de los mejores sería escrito por el español Adolfo Rivadeneyra. Pero además, este viaje daría origen a un cuadro singular, que se cuenta entre los más interesantes de la pintura orientalista española. Su consideración y su recuerdo son reflejo de los avatares que la ciencia dedicada a Oriente ha seguido en España hasta fechas muy recientes.
\end{abstract}

\section{PALABRAS CLAVE:}

Adolfo Rivadeneyra, viajes por Irán, pintura orientalista

\begin{abstract}
Several Europeans travellers journeyed throughout the Near East and Iran during the XIX century. Many of them left an indelible memory in these relevant books, in which they described the ruins, customs and landscapes. Adolfo Rivadeneyra wrote one of the best works. In addition, his journey gave rise to a singular painting, one of the most interesting examples of the Spanish Orientalist Paintings. His importance and memory reflects the vicissitudes in regard to the Spanish science devoted to the Oriental World until recent times.
\end{abstract}

KEY WORDS:

Adolfo Rivadeneyra, journeys through Iran, Orientalist painting.

1 En homenaje y muestra de admiración y cariño al Prof. Dr. Don Federico Lara Peinado, profesor y maestro de Historia de Oriente Próximo, en la Universidad Complutense de Madrid.

2 Universidad Autónoma de Madrid: joaquin.cordoba@uam.es 
Hace ya un par de años, el Museo Arqueológico Nacional de España empezó una necesaria reforma del edificio y la reordenación de sus fondos. Como se ha indicado en la prensa en más de una ocasión ${ }^{3}$, las obras suponen una modernización completa del mismo, cuyas salas de exposición podrán ampliarse y adaptarse a las nuevas tendencias museográficas. Quizás sea ésta la ocasión mejor para que un cuadro al óleo de José Luis Pellicer Feñé, que evoca el viaje de Adolfo Rivadeneyra por Irán, y que no ha mucho vistió los muros del museo, en el curso de una exposición sobre la aportación española al redescubrimiento de Oriente Próximo antiguo, pueda integrarse definitivamente en los fondos expuestos. Se recordaría así a quienes durante el siglo XIX, en Oriente o en cualquier otro rincón de España y el mundo, empezaron a reunir los objetos y documentos que algún día serían patrimonio de nuestro museo. De aquellos eruditos pacientes y viajeros valerosos descienden los que, durante la segunda mitad del $\mathrm{XX}$, han dedicado sus esfuerzos a que en nuestras aulas universitarias, la Historia del Oriente Próximo Antiguo encuentre su imprescindible espacio junto a las de Roma, Grecia o España antigua. Por eso, también hoy, la evocación de este cuadro sirve de homenaje a su vida y su tesón.

\section{DE LA VIDA, OBRA Y VIAJES DE ADOLFO RIVADENEYRA}

En la actualidad, la vida y la obra de Adolfo Rivadeneyra (1841-1882) son muy bien conocidas, gracias a los esfuerzos de algunos investigadores en particular, como Lily Litvak o Fernando Escribano Martín. Porque si es verdad que su persona mereció una entrada en la primera edición y siguientes de la magnífica Enciclopedia Espasa ${ }^{4}$, no lo es menos que con los avatares políticos e históricos sobrevenidos durante la primera mitad del siglo $\mathrm{XX}$, que tan profundamente afectaron a nuestra ciencia y cultura, su recuerdo quedaría poco a poco circunscrito al de contados eruditos. Felizmente, eso ya no es así. Estudios monográficos sobre su persona y su obra ${ }^{5}$, reelaboraciones de algunos de sus viajes ${ }^{6}$, nuevas ediciones de sus libros más emblemáticos ${ }^{7}$, su presencia y recuerdo en diccionarios espe-

${ }^{3}$ Por ejemplo, en la revista Metrópolis, del diario El Mundo, páginas 4 y 5 de su edición de 27 de enero del año 2012, o en las páginas 80 y 81 del diario ABC de 4 de marzo del año 2012, en artículo firmado por Natividad Pulido.

4 «Rivadeneyra (Adolfo)», Enciclopedia Universal Ilustrada Europeo-Americana, Espasa Calpe, S. A., Madrid 1926, Tomo LI, pág. 883, que le dedica casi una columna de texto esmerado.

5 ESCRIBANO MARTíN, F.- Adolfo Rivadeneyra (1841-1882). Diplomacia, viajes y erudición en su redescubrimiento de Oriente. Universidad Autónoma de Madrid, Madrid 2001. Una nueva edición, en prensa.

6 LITVAK, L..- Viaje al interior de Persia. El itinerario de Rivadeneyra (1874-75). Ediciones del Serbal, S. A., Barcelona 1987. La autora prologó además una edición que la editorial Laertes hizo en 1988 de la primera obra de viaje de A. Rivadeneyra, De Ceylán a Damasco (1871), no tanto del libro entero, con sus largos apéndices, cuanto del texto que el autor dedicara estrictamente a narrar a su viaje. Se publicó así: RIVADENEYRA, A.- De Ceilán a Damasco. Laertes. S. A. de Ediciones, Barcelona 1988. El prólogo de L. Litvak, en las páginas 7 a 16.

7 RIVADENEYRA, A.- Viaje de Ceilán a Damasco. Edición, prólogo y notas de Fernando Escribano Martín. Miraguano, S. A. de Ediciones, Madrid 2006. Viaje al interior de Persia. Edición, prólogo y notas de Fernando Escribano Martín. Miraguano, S. A. de Ediciones, Madrid 2008. 
Rivadeneyra en Dizful. Notas sobre un óleo dedicado a la aventura...

cializados, obras generales o exposiciones nacionales ${ }^{8}$, una nutrida serie de trabajos científicos ${ }^{9}$, incluso su no rara aparición en artículos divulgativos de prensa y revistas culturales ${ }^{10}$ le han llevado a convertirse en uno de nuestros viajeros a Oriente más populares. Así pues, estando hoy bien trazada su semblanza biográfica $^{11}$, cualquier referencia a ella ha de pecar de reiteración. Pero me veo obligado a traerla de nuevo a colación, pues algunos datos acaso expliquen mejor la naturaleza y el significado profundo de su gran viaje por Irán, así como el simbolismo encerrado en el cuadro de José Luis Pellicer. Fue hijo de Manuel de Rivadeneyra y Ruiz, celebérrimo editor de la Biblioteca de Autores Españoles, un hombre inquieto y curioso, impresor de profesión, que al viajar y ejercer su oficio en numerosos países, llevando consigo a su familia, ayudó en parte a que su hijo Adolfo siguiera el camino que cumplió, y que recibiera excelente educación cosmopolita y políglota. Nació pues Adolfo en Chile, el 10 de abril de 1841. A los siete años sus padres volvieron a España, iniciando Adolfo su educación en el colegio de Masarnau y el Seminario de Vergara, aunque poco después continuaría sus estudios en París, y más tarde, en Bélgica y Alemania, tanto en interés de la mejor formación académica posible, como por el deseo paterno y de él mismo de adquirir las len-

8 LITVAK, L.- Geografías mágicas. Viajeros españoles del siglo XIX por países exóticos (18001913). Laertes S. A. de Ediciones, Barcelona 1984, 117-128, 163-167: El ajedrez de las estrellas, Editorial Laia, Barcelona 1987, donde se cita a A. Rivadeyra en numerosos ocasiones. GARCÍA-ROMERAL PÉREZ C.- Bi-bibliografía de Viajeros Españoles (Siglo XIX). Ollero \& Ramos, Editores, Madrid 1995, págs. 218-219: Diccionario de viajeros españoles. Desde la Edad Media a 1970. Ollero y Ramos, Editores, S. L., Madrid 2004, págs. 390-391. CÓRDOBA, J. Mª y PÉREZ DÍE, Ma C. (eds.).- La aventura española en Oriente (1166-2006). Viajeros, museos y estudiosos en la historia del redescubrimiento del Oriente Próximo Antiguo. Ministerio de Cultura, Madrid 2006. En aquella exposición, celebrada entre los meses de abril y junio del año 2006, se expusieron portadas de sus libros, varias fotografías y el cuadro que nos ocupa, a más de citársele en distintas páginas y dedicársele un artículo monográfico.

9 CÓRDOBA, J. Ma -- «La percepción del Irán antiguo y contemporáneo en la obra de los viajeros españoles de los siglos XVII y XIX», en CÓRDOBA, J. M-, JIMÉNEZ ZAMUDIO, R. y SEVILLA CUEVA, C. (eds.).- El redescubrimiento de Oriente Próximo y Egipto. Viajes, hallazgos e investigaciones. Universidad Autónoma de Madrid, Madrid 2001, págs. 1-15. ESCRIBANO MARTíN, F.- «Adolfo Rivadeneyra. La diplomacia al servicio del redescubrimiento científico y vital de Oriente», ISIMU 5 (2002), págs. 45-100: "Adolfo Rivadeneyra, un diplomático español al servicio del estudio y del viaje a Oriente» $A R B O R$ CLXXX, 711-712 (2005), 789-804: «Un gran viajero, arqueólogo y pionero en Oriente: Adolfo Rivade-

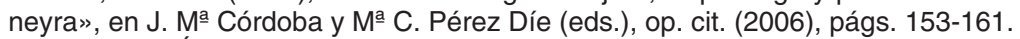

10 RODRÍGUEZ CABALLERO, A. Ma. - «El periplo decimonónico de Rivadeneyra (Las antigüedades orientales del Museo Arqueológio Nacional)», El Punto de las Artes, 5 al 11 de junio (1998), pag. 15: «En un mercado persa. Rivadeneyra y el comercio de antigüedades», El Punto de las Artes, 16 al 12 de abril (1999), pág. 19: «Una muestra de Oriente en Madrid. En la Sacramental de San Isidro», El Punto de las Artes, 3 a 9 de noviembre (2000), pág. 17: "Adolfo Rivadeneyra. Un orientalista español del siglo XIX» Revista de Arqueología, 456 (1999), págs. 52-55. ESCRIBANO, F. y LEAL, J. F.- «Adolfo Rivadeneyra en Persia», Magazine de El Mundo, 456 (2008), págs. 30-32.

11 Me remito esencialmente a lo recogido e indicado por F. Escribano Martín en la obra arriba citada -Op. Cit. (2001) - y en sus prólogos a las ediciones de Viaje de Ceilán a Damasco (Op. Cit. 2006, págs.. 9-26) y Viaje al interior de Persia (Op. Cit. 2008, págs.. 20-43). Igualmente, véase SAAVEDRA, E."Discurso en elogio de D. Adolfo Rivadeneyra», Boletín de la Sociedad Geográfica de Madrid, XII (1882), págs.. 495-513. Además, es muy interesante la sentida necrológica que firmara Eusebio Martínez de Velasco, a poco de su fallecimiento, con el título «Don Adolfo Rivadeneyra y Sánchez. Literato y orientalista», y publicada en La llustración Española y Americana, Año XXVI, nº XL, de 22 de marzo de 1882, en su pág. 179. Hoy no deja de resultar raro, aunque fuera práctica habitual entonces en las artes gráficas, que se publicara en la página siguiente, entre texto de otro artículo con el que nada tenía que ver el óbito, un grabado con el perfil de Adolfo Rivadeneyra. 
guas extranjeras. De hecho -y además de las lenguas clásicas- llegaría a dominar con fluidez el francés, inglés, italiano y alemán y, más tarde, varias orientales como el árabe, el turco y el farsí. Con tales aptitudes e inquietudes culturales es lógico que buscara futuro en la diplomacia. A los veinte años solicitó su integración en el primer rango del cuerpo diplomático de entonces - joven de lenguas-, mediante escrito de 21 de diciembre de 1863, elevado ante la reina Isabel II, pidiendo plaza en alguno de los consulados de Oriente $^{12}$. Y empezaría así, casi de inmediato, su ancho y brillante servicio en el exterior, al ser destinado el 29 del mismo mes al Consulado General de España en Beirut, donde tomó posesión el 1 de marzo del siguiente año. Como es bien sabido ${ }^{13}$, su carrera se desenvolvió fundamentalmente en los países de Oriente Próximo, además de Ceilán y Marruecos. Estando aún en Beirut fue encargado en dos ocasiones del Consulado de España en Siria, con sede en Jerusalén: durante dos meses en 1864, y otros seis meses en 1866. En 1867 fue nombrado vicecónsul en Beirut, pero en noviembre del mismo ejercicio lo sería a su vez como vicecónsul en Colombo (Ceilán). Prestó allí sus servicios apenas otro año más, pues en noviembre de 1869 recibió nueva orden de presentarse en Damasco, donde a partir de entonces había de actuar como vicecónsul de España en la Turquía Asiática. Para alcanzar su nuevo puesto emprendió un viaje esforzado y magnífico, que entre mayo y agosto de 1869 le llevaría por mar desde Colombo a Bombay, el Golfo Pérsico y Basra, por el curso del Tigris luego hasta Bagdad, y a caballo por Kirkuk, Mossul, Dyarbakir y Aleppo hasta su etapa final en Damasco. Fruto de tan singular viaje sería su primer gran libro y los apéndices que le acompañaban, el Viaje de Ceylán (sic) a Damasco (1871) ${ }^{14}$. Pero a finales de 1870 volvió a España, a la espera de una nueva comisión que no se materializaría hasta el 14 de diciembre de 1873, cuando el gobierno de Emilio Castelar le nombrara vicecónsul en Teherán. Y con ese nombramiento entramos ya en la materia principal de estas líneas.

Como digo más arriba, no es mi intención reconsiderar aquí la vida o la obra de Adolfo Rivadeneyra, sino tan sólo explicar las circunstancias y el simbolismo que se me antoja ver en el cuadro que José Luis Pellicer dedicó a un episodio de su viaje por Irán. Pero ello me obliga también a dedicar mayor atención al periodo de su vida que lo relaciona con aquél país. La política exterior española en la región era escasa. El gobierno de Isabel II había comenzado a abrir consulados en las provincias del Imperio Otomano, y tímidamente, nuestro país empezó a comprometerse con la “cuestión de Oriente» ${ }^{15}$, a remolque en parte de la política francesa. Mas Irán o Persia, como se decía entonces, resultaba particularmente lejano a nuestros intereses, a más de ser bien conocido en las cancillerías europeas que Rusia e Inglaterra lo

12 ESCRIBANO MARTÍN, F., Op. Cit. 2008, pág. 24.

13 Me reitero en la información facilitada por F. Escribano Martín en las obras ya citadas (Op. Cit. 2001 y 2008)

${ }_{14}$ A destacar la edición y el prólogo de F. Escribano Martín, arriba citada (Op Cit. 2006).

15 MARTÍN ASUERO, P.- Viajeros hispánicos en Estambul. De la cuestión de Oriente al reencuentro con los sefardíes (1784-1918). Editorial Isis, Estambul 2005, págs. 13-30: «Los diplomáticos españoles y el redescubrimiento del Imperio Otomano», en CÓRDOBA, J. Mª y PÉREZ DÍE, M. C. (eds.), op. cit. 2006, págs. 133-141. 
Rivadeneyra en Dizful. Notas sobre un óleo dedicado a la aventura...

consideraban espacio propio de influencia, disputándose hacía tiempo el ejercicio de un cierto protectorado sobre Teherán. Pero como la Dinastía Q rí (1795-1925)", disgustada frecuentemente con ambas potencias, buscaba a veces equilibrar la influencia y los negocios de aquellas con otros estados, un nuevo gobierno español quiso verificar si existían posibilidades de acción para España en Irán. Reinaba entonces $\mathrm{N}$ ser al Din (1848-1896), monarca muy culto, viajero ${ }^{1}$, deseoso de modernizar su país, pero sometido a fuertes presiones internas y externas que le hicieron desprenderse incluso de su mejor ministro, el gran reformador de Irán, Am $r$ Kab r (1807-1852). Y a aquella nación que se estaba esforzando por consolidar avances como el telégrafo, el correo, las carreteras, una universidad politécnica, un ejército y una policía moderna, y que se estaba viendo obligada a ceder a compañías extranjeras suntuosos negocios, despachó Emilio Castelar a Adolfo Rivadeneyra como vicecónsul, según nombramiento de 17 de septiembre de 1983, con la misión añadida - pero esencial- de estudiar nuestras posibilidades comerciales $^{18}$. De su largo trayecto hasta Teherán, de su estancia allí, del desarrollo de su misión diplomática, así como y sobre todo, de su largo viaje por el interior de Irán, estamos particularmente bien informados gracias a uno de los mejores libros de viaje de la época, su Viaje al interior de Persia (1880), y naturalmente, gracias a los minuciosos informes que remitiera al gobierno español desde su delegación ${ }^{19}$. Apenas repuesto del duro camino seguido hasta la capital persa, el vicecónsul español se entrevistó con los representantes europeos, a la mayor parte de los cuales conocía de anteriores coincidencias: Beguer, decano del cuerpo y ministro de Rusia -cónsul en Beirut, cuando él había sido allí joven de lenguas-, el francés Mellinet -que había hecho carrera en Cuba-, el británico Thompson, antiguo residente en Chile-, el turco Munif Effendi —originario de Siria, que Rivadenyra conocía tan bien- y el ministro de Austria, conde Dubsky, que anteriormente se había desempeñado como primer secretario de la embajada de su país en Madrid. Con ellos y con el resto de la colonia europea supo anudar las mejores relaciones de amistad y cooperación. Pero más complejo sería el caso, al principio al menos, con las autoridades iraníes. Hussein Jan, ministro de negocios extranjeros y favorito del monarca, tardó en recibirle, considerando con razón, que la condición de vicecónsul que ostentaba Rivadeneyra confería a su representación un rango diplomático menor. Pero en fin, tras cinco meses de residencia en Teherán, durante los cuales además de ejercer sus obligaciones diplomáticas, aprovechó para estudiar la lengua persa con notable fruto, se propuso llevar a cabo un largo viaje por el interior del

16 KAVANAGH, A. G.- Irán por dentro. La otra historia. José J. de Olañeta, Editor, Palma 2010, págs. 100-110. KHEZI, A. A. R. et alii.- Persia. Cuna de civilización y cultura. Editorial Almuzara, Córdoba 2011, págs. 94-103.

17 Emprendió varios viajes a Europa. Fruto de uno de ellos sería un curioso libro publicado luego en persa, inglés, francés, alemán y holandés. La versión inglesa se titulaba $A$ diary kept by His Majesty the Shah of Persia during his journey to Europe in 1878, en R. Bentley \& Son, London 1879.

18 ESCRIBANO MARTÍN, F., Op. Cit. (2006), pág. 19.

19 ESCRIBANO MARTÍN, F., Op. Cit. (2001): Op. Cit. (2008), págs. 33-35.

20 RODRÍGUEZ ESTEBAN, J. A.- Geografía y colonialismo. La Sociedad Geográfica de Madrid (1876-1936), Universidad Autónoma de Madrid, Madrid 1996, pág. 67. Según E. Saavedra, aquella conferencia la dictó el 22 de abril de 1876. Véase SAAVEDRA, E., Op Cit. (1882), pág. 496. 
país, a fin de estudiar directamente el movimiento comercial —objetivo de su misión, al fin y al cabo-, y conocer de primera mano los paisajes, monumentos, gentes y costumbres de Irán. El 19 de septiembre partió de la capital, a la que no volvería hasta casi un año después, el 24 de agosto de 1875. Algo enfermo, solicitó una licencia, dejando Teherán el 1 de octubre de aquel año. Pero lo que parecía un simple y obligado paréntesis sería definitivo, porque un nuevo gobierno en Madrid decidió cerrar la delegación diplomática en Irán, dejando sin efecto el trabajo realizado, las relaciones trazadas y las buenas expectativas abiertas. Una vez más, la falta de visión de estado dejaba sin fruto los sacrificios y esfuerzos de los mejores representantes de nuestro país.

De vuelta a España, desde 1876 se integraría activamente en las actividades y organización de la Sociedad Geográfica de Madrid, de la que fue vocal y secretario de su primera Junta Directiva, así como su primer conferenciante ${ }^{20}$, habiendo dictado precisamente, una exposición sobre Irán, su geografía y sus habitantes. En 1878 fue ascendido a cónsul de segunda clase, con residencia en Singapur, aunque no llegó a tomar posesión, dado que algunos días después se le nombró cónsul de España en Mogador. No le fue fácil el desempeño de aquella misión, por lo que el 22 de septiembre de 1879 pidió traslado. Según todos los indicios, éste fue su último destino. A poco aparecieron los tres volúmenes de su Viaje al interior de Persia (1880), obra de la que ofreció dos ejemplares al ministerio de Asuntos Exteriores, según carta de 21 de marzo del año siguiente ${ }^{21}$. Pero fatalmente y cuando nada hacía suponerlo, un año más tarde y con apenas cuarenta y un años de edad, murió el 6 de febrero de 1882, tras padecer algún tiempo una enfermedad que, según escribió Eusebio Martínez de Velasco, había contraído en su viaje a Irán²2. La muerte de Adolfo Rivadeneyra supone la temprana pérdida de nuestro mejor pionero del siglo XIX, un hombre con capacidad suficiente como para haberse convertido en nuestro P. E. Botta o nuestro A. H. Layard, pues en nada desmerecía frente a ellos en intuición arqueológica, en conocimientos, en adaptación al medio o en amor a la Antigüedad ${ }^{23}$. Le faltó, eso sí, vida y un gobierno capaz de entender los intereses que se estaban entonces dirimiendo en Oriente. Pero sus obras y su persona siguen constituyendo un referente imprescindible.

\section{DEL VIAJE POR IRÁN Y, SOBRE TODO, DE LA ENTRADA EN DIZFUL}

Escribía Adolfo Rivadeneyra en las páginas de su libro, fechando el capítulo VII del primer volumen en Teherán, el 16 de septiembre de 1874, que decidido a cum-

21 ESCRIBANO MARTÍN, F., Op. Cit. 2008, pág. 28.

22 MARTÍNEZ DE VELASCO, E., Op. Cit. (1882), pág. 17. Según escribiera E. Saavedra -Op. Cit. (1882), pág. 511)- se trataba de un aneurisma, que en sus últimos días le obligaba a estar «clavado en un sillón en actitud incómoda»... "las horas del día y de a noche sin exhalar una queja».

${ }^{23}$ CÓRDOBA, J. Mํa -- «Del Éufrates y el Tigris a las montañas de Omán. Algunas observaciones sobre viajes, aventuras e investigaciones españolas en Oriente Próximo», ARBOR CLXI 635-636 (1998), págs. 441-463. Vid. pág. 453. 
Rivadeneyra en Dizful. Notas sobre un óleo dedicado a la aventura...

plir su misión -informar sobre el comercio de Irán-, y aunque bien podría haberlo hecho desde casa, valiéndose de observaciones y datos reunidos por terceros, resolvió lanzarse «a recorrer el país en todos los sentidos» 24 . Se puso pues a preparar concienzudamente un viaje que quería fuera al tiempo de exploración y estudio, en el curso del cual iría tomando la multitud de datos que luego darían cuerpo a sus magníficos informes oficiales y al excelente libro en tres tomos que vendría a publicar cinco años después. Cuidó además de adquirir un buen conocimiento de la lengua persa y su escritura, de los sistemas vigentes en monedas, pesos o medidas, y de las costumbres propias del país referidas al trato. Conocedor de los libros y viajes seguidos por otros europeos antes que él, como Burnes, Fraser, Vambéry, Goldsmid, Bode, Layard, Hauskenesht, Rawlinson, Loftus o Flandin y Coste, quiso «para prestar servicios a la geografía y al comercio, ... dejar los itinerarios seguidos y adoptar uno nuevo "25. Pero las dificultades extremas de las que fue avisado, la inseguridad y la carencia de todo fuera de contadas rutas le obligaron a atemperar sus planes, evitando al menos recorrer dos veces los mismos sitios y adaptando su ruta a las estaciones. Así pues, pensó dirigirse primero a Hamadán y Kermanshah, pasando luego por el Loristán y Arabistán, donde quería permanecer en diciembre. Luego, iría a Bushir y desde allí, en abril, marcharía por Firuzabad y Darab a Carmania, para regresar en julio por el Sistán y Meshed. Calculaba pues estar de regreso en octubre, tras recorrer «unas mil setecientas leguas por trayectos de a ciento» ${ }^{26}$, que era la distancia media entre dos capitales de provincia. Además de preparar su itinerario buscó los necesarios servidores que habían de seguir camino con él, imprescindibles en un cierto número si quería ser bien acogido, dado que en Irán se medía la importancia de la persona viajera por el número de sus acompañantes. Reclutó a un secretario armenio, llamado Mirza Abcar, encargado de saludar en su nombre a las autoridades de los lugares a los que llegaran, de recoger noticias siguiendo un cuestionario que le facilitó, y en fin, de vigilar a los criados. Entre éstos tomó a su servicio a un cocinero natural de Shiraz, así como a un criado de Bushir. Con ellos decidió formar una pequeña caravana, alquilando caballos que luego iría renovando en camino. Como equipaje cuenta que iba a llevar consigo una cama, dos mudas, un traje para presentarse ante las autoridades, otro de viaje con botas y pantalones de montar, chaleco, chaquetón, capote forrado de piel, gorro de lo mismo y «salacó o sombrero de tinsin, pues he de sufrir gran variedad de temperaturas y para todas necesito apercibirme ${ }^{27}$. Llevaba además cuadernos de notas, papel secante para colocar las plantas que le llamaran la atención, un termómetro y una brújula, junto con algunos libros para distraerse, como las obras de Duncker y Heródoto, o el relato del viaje hecho por el shah N ser al Din a Europa, escrito por el mismo monarca. Prefirió no cargar con ninguno de los escritos anteriormente por otros via-

24 RIVADENEYRA, A.- Viaje al interior de Persia. Imprenta y estereotipia de Aribau y Cía., Madrid 1880, tomo I, pág. 331.

25 RIVADENEYRA, A., Op. Cit. (1880), tomo I, pág. 352.

26 RIVADENEYRA, A., Op. Cit. (1880), tomo I, pág. 355.

27 RIVADENEYRA, A., Op. Cit. (1880), tomo I, pág. 376. 
jeros europeos, para no llevar «prevenida la imaginación» ${ }^{28}$. Recogidas en fin las provisiones necesarias, una carta circular de su alteza Hussein Jan -en la que instaba a los responsables de provincias y localidades a prestar ayuda a «mussiú Adúlf, de elevado rango, que la grandeza le acompañe, Cónsul pequeño ${ }^{29}$ del excelso Gobierno español, y su Residente cerca del Sublime Gobierno» ${ }^{30}$-, y algunas otras de recomendación de sus amigos, como una carta del ministro de Rusia, dirigida a Heshmed Eddaulet, tío del shah y gobernador del Loristán y el Arabistán, acabó sus preparativos y fijó fecha para ponerse en camino. Y así, el 19 de septiembre del año 1874 emprendió la marcha hacia la ciudad de Savah, con la pequeña caravana que integraba con su secretario armenio, sus criados, animales y los mozos correspondientes.

En el curso de un viaje minuciosamente narrado en los otros dos volúmenes de su obra y trazado en un mapa que produce sincero asombro, Adolfo Rivadeneyra fue pasando por ciudades legendarias, ruinas de evocación poderosa y paisajes de inenarrable escabrosidad o belleza. Sin entrar en detalles, baste recordar que pasó por Abdul Azim, el extraño cementerio y torre del silencio de los zoroastrianos en Chesme Ali, los cercanos relieves de Fet Ali Shah, la ciudad de Savah, Hamadam — donde recuerda haberse encontrado la meda Ecbatana-, las inscripciones cuneiformes rupestres de Alvend, las ruinas de Quingavar, Behistun sus inscripciones y relieves, Kermanshah, los relieves y nichos de Taq-i Bustán, Jorramabad, donde encontró al gobernador general del Loristán, Heshmed Eddaulet, tío del shah, para el que tenía una carta de su amigo Beguer, ministro del zar. En el curso de una entrevista con él, Rivadeneyra supo ganar la simpatía del poderoso pariente del monarca, quien sabedor de que el español se dirigía a Dizful le invitó a acompañarle, pues "me será muy grato viajar en vuestra compañía; tanto más cuanto que caminando solo correríais grandes peligros» ${ }^{31}$. La llegada a Dizful ocasionaría la rutilante escena que luego pintaría J. L. Pellicer, como veremos enseguida. Tras larga estancia en Dizful, en el curso de la cual visitó la cercana Shuster, prosiguió su ruta pasando por Susa —donde visitaría el supuesto sepulcro del profeta Daniel y las ruinas antiguas, en las que como bien recordaría, hacía poco había trabajado Loftus ${ }^{32}$ _, y tras largas dificultades, alcanzó Feiliyé, a orillas del curso ya unido del Tigris y el Éufrates, próxima a la desembocadura en el Golfo Pérsico. Partió luego por barco rumbo a Bushir, donde desembarcó el 29 de enero de 1875, recibiendo amistosa hospitalidad del coronel Ross, residente británico.

28 RIVADENEYRA, A., Op. Cit. (1880), tomo I, pág. 380.

29 La lengua persa traducía así la categoría de vicecónsul, condición dada por el gobierno español a su representante diplomático en Teherán, lo que ocasionó un notable desagrado a las autoridades iraníes. Con esa condición, A. Rivadeneyra sabía que no podía esperar excesivas atenciones de las autoridades provinciales en el curso de su viaje.

30 RIVADENEYRA, A., Op. Cit. (1880), tomo I, págs. 381-382.

31 RIVADENEYRA, A.- Op. Cit. (1880), tomo II, pág. 171. La simpatía fue recíproca. A. Rivadeneyra destaca cómo llegó a conocerle a lo largo del tiempo que compartieron juntos, en el viaje y en el mismo Dizful, y del sincero afecto que ambos se profesaron, bien testimoniado en la despedida. Asi, véase, Op. Cit. (1880), tomo II, págs. 287-288.

32 RIVADENEYRA, A.- Op. Cit. (1880), tomo II, pág. 308. 
Rivadeneyra en Dizful. Notas sobre un óleo dedicado a la aventura...

Tres semanas después reanudó la marcha hacia las montañas del interior. Pasó por las ruinas de la antigua ciudad de Shapur -admirando los relieves sasánidas y la famosa gruta con la colosal estatua de seis metros del monarca-, Kazrun y Shiraz, donde visitaría la tumba de Hafiz. Y luego Firuzabad y sus inmensas ruinas, Kerman y Yezd. Diversas circunstancias le impidieron seguir la ruta proyectada hacia el Sistán, por lo que hubo de volver a Shiraz por distinto camino, visitando en esta ocasión las ruinas de Persépolis —en las que recordaría a Ker Porter, Coste y Flandin, y que describiría pormenorizadamente ${ }^{33}$ - y los relieves y las tumbas reales de Naqs-i Rustam. En fin, el 16 de julio enderezó sus pasos hacia Isfahán, y tras una maravillada estancia en la famosa ciudad, siguió su larga ruta hasta entrar de nuevo en Teherán, el 24 de agosto de 1875. Detrás quedaba una experiencia única, centenares de páginas llenas de notas y la idea de un libro que llegaría a ver la luz en Madrid, no mucho después. Pero volvamos al episodio de su entrada en Dizful, que junto al cuadro de J. L. Pellicer motiva estas páginas.

Tras abandonar Jorramabad, y dejando atrás el siempre problemático país de los loris, el séquito de Heshmed Eddaulet entró en Arabistán. A. Rivadeneyra describiría detenidamente la jornada ${ }^{34}$, empezada la tarde anterior, cuando la caravana alcanzó Salehabad. Comenzaron entonces a acercarse hasta allí las gentes y autoridades de Dizful, para presentar sus respetos al gobernador y pariente del shah. Más de cien jinetes encabezados por su sobrino, notables, comerciantes, imanes, oficiales del ejército ... todos entraban poco a poco en la tienda del gobernador y besaban el borde de su levita. Muchos pernoctaron allí «para aumentar el esplendor y solemnidad del recibimiento que se preparaba al día siguiente». Al amanecer de aquel 1 de enero, el ispaniulu que tomaba su té al aire libre sentado en una alfombra, llamaba la atención de todos. A las ocho y media salió de su tienda Hesmed Eddalet, "vestido de medio uniforme, con preciosa espada»... «montó su mejor yegua alazana» ... y ... «en cuanto me vio, «ya no tendréis que tomar notas de viaje, dijo, y desde este momento quiero teneros a mi lado». Coloquéme a su izquierda y principiamos a caminars ${ }^{35}$. Encabezaban el cortejo, lejos de ellos, los caballos de respeto, y media docena de jinetes que simulaban combatir, escaramuceando y corriendo de un lado para otro. Luego, tras el gobernador y sus más directos allegados iba una gran escolta de caballería irregular, formada por personas de toda clase, "con trajes de brillantes colores». A la media hora de marcha se distinguieron algunas palmeras y las casas de Dizful, y según avanzaban iban uniéndose más y más jinetes, que tras saludar al gobernador pasaban a engrosar la escolta. Tras una ondulación del terreno apareció un gentío clamoroso, vestido con «los trajes más galanos». Unos esperaban tranquilos, otros aceleraban el paso. Tres se acercaron a los pies del caballo del gobernador, llevando grandes corderos «cuyas cabezas cortaron de un solo golpe, pasando la yegua sobre la sangre»... «a un lado del camino, otros cuatro sujetaban un camello que decapi-

\footnotetext{
33 RIVADENEYRA, A.- Op. Cit. (1880), tomo III, págs. 209-227.

34 RIVADENEYRA, A.- Op. Cit. (1880), tomo II, págs. 242-247.

35 RIVADENEYRA, A.- Op. Cit. (1880), tomo II, págs. 242-243.
} 
taron, ofreciendo la cabeza a S. A.»36. Los sacrificios se multiplicaban: ovejas, cabritos, camellos, vacas blancas ... Cuando la yegua del gobernador pisaba la sangre, «la multitud prorrumpía en invocaciones atronadoras». Un descendiente del profeta, envuelto en traje talar verde y tocada la cabeza con turbante del mismo color, ofreció al gobernador un anillo de oro. Todo aquello superaba cuanto Rivadneyra podía haber imaginado. La impresión tuvo que ser muy fuerte, pues escribe que «no sabía dónde fijar la ansiosa mirada; todo lo quería ver, todo lo quería oir». Observó a su derecha un grupo de derviches en fila, algunos con gorros cónicos, muchos medio desnudos, exclamando a coro «iAli! ... ¡Ali!», y en medio de aquel griterío y estruendo distinguía la voz de los sacrificadores, que al matar a sus víctimas levantaban los puñales y clamaban « iOh Dios, saludos a Mahoma y a los mahometanos!». Y los miembros del servicio tiraban monedas a la multitud, que pugnaba también por hacerse con restos de los animales sacrificados. Cesó finalmente el delirio por orden del gobernador, reordenándose el cortejo, y colocándose cuatro cañones delante de la comitiva, que hicieron salvas en su honor. Poco a poco, llegó ésta por fin al palacio que se levantaba en la orilla septentrional del río. Y después de que Heshmed Eddaulet pasara una revista y atendiera el homenaje popular — momentos a los que asistió Rivadeneyra, expresamente invitado por el gobernador-, nuestro viajero pudo retirarse a la vivienda a él destinada, tras una jornada «cuyo recuerdo quedará siempre grabado en mi memoria»37. Mal podría imaginar que aquella fascinante jornada, convertida en el color y la luz de un lienzo singular, andando el tiempo llegaría a convertirse en el símbolo más poético y veraz al tiempo de la aventura española en Oriente, del esforzado tesón de sus pioneros.

\section{EL CUADRO DE JOSÉ LUIS PELLICER Y SUS AVATARES}

Como escribiría luego expresamente en las páginas de su libro, aquella tremenda algarabía, la luz de la mañana, la abigarrada multitud, la música y las vociferantes exclamaciones, lo suntuoso del cortejo y el clamor de quienes saludaban la entrada del gobernador impresionaron de manera especial al vicecónsul español. Lo asevera aún más que, de vuelta a España, encargara al pintor José Luis Pellicer Feñé un lienzo en extremo singular, que evocaba aquel momento y ningún otro de su experiencia en Irán. Y es que, si bien es cierto que amaba las ruinas y sabía verlas con la intuición del arqueólogo, ni las impresionantes de Persépolis o las más remotas aún de Bishapur, ni las torres del silencio zoroastrianas o la colina de Susa encendieron tanto sus recuerdos como aquel instante único, asombroso, fascinante, vivido entre el fragor de gritos y cantos en una llanura meridional de Irán, camino de Dizful. Pues bien, los avatares de este cuadro y su permanente simbolismo constituyen la esencia de cuanto quiero decir con estas notas sobre Rivadeneyra.

36 RIVADENEYRA, A.- Op. Cit. (1880), tomo II, págs. 244.

37 RIVADENEYRA, A.- Op. Cit. (1880), tomo II, págs. 247. 
Rivadeneyra en Dizful. Notas sobre un óleo dedicado a la aventura...

En el sentido elogio fúnebre que el 28 de marzo de 1882 le dedicó a su memoria el sabio arabista y presidente de la Sociedad Geográfica de Madrid, Eduardo Saavedra $^{38}$, en sesión celebrada con tal objeto apenas mes y medio después de su fallecimiento, recordaba el orador «la solemne entrada en Dizful, perpetuada por el pincel de Pellicer en el cuadro que hoy adorna el salón donde los ministros se reúnen en Consejo»39. Y ello era así, porque, entre las disposiciones hechas por Adolfo Rivadeneyra en su testamento ${ }^{40}$, consta legado al gobierno español de aquel cuadro que, como revela la mención de E. Saavedra y algunas referencias bibliográficas, llegaría a tener cierta fama. Sin embargo, poco a poco caería en el olvido, quedando como un mero y algo exótico adorno de las dependencias ministeriales. Hasta su título real llegaría a perderse, siendo al fin etiquetado en algún inventario indocumentado, con un delirante título y descripción. Razón de más para recordar ahora las circunstancias de su creación, su pérdida y su recuperación.

Adolfo Rivadeneyra abandonó Teherán a comienzos de octubre de 1875, alegando su estado de salud «bastante quebrantada por la fiebre» ${ }^{41}$. Una vez en el Madrid de la Restauración, el nuevo gobierno salido de las elecciones de enero de 1876 decidió clausurar la representación en Teherán. A la espera pues de nuevo destino, Rivadeneyra se dedicó a escribir su libro y distintas colaboraciones, así como a las actividades de la Sociedad Geográfica de Madrid, que animaba Eduardo Saavedra. Pero también apenas llegado a la capital le encargó al pintor José Luis Pellicer, celebrado ilustrador de la prestigiosa La Ilustración Española y Americana y otras publicaciones, un cuadro al óleo que quería quizás como recuerdo propio de aquel momento fascinante, vivido en la entrada a Dizful. La elección de Pellicer no podía ser más certera, porque si bien éste había pintado algún lienzo "oriental», bajo la influencia de Mariano Fortuny, lo cierto es que el pintor barceIonés tenía bien ganado prestigio de pintor realista. $Y$ es más que probable que Adolfo Rivadeneyra buscara no tanto el exotismo pintoresco y ensoñador de la pintura orientalista al uso, cuanto la certera recreación de su aventura y del mundo que había vivido.

José Luis Pellicer (1842-1901) ${ }^{42}$ tenía casi la misma edad que Rivadeneyra. Nacido en Barcelona, se había formado como pintor en el taller de Ramón Martí Alsina (1826-1894), uno de los mejores representantes del realismo en España. En 1865

${ }_{38}$ Arabista e historiador positivista, al decir de B. López García, autor entre otras muchas obras de interés de un clásico Estudio sobre la invasión de los árabes en España. Así LÓPEZ GARCíA, B.- Orientalismo e ideología colonial en el arabismo español (1840-1917). Universidad de Granada,Granada 2011, págs. 351-352.

39 SAAVEDRA, E.- Op. Cit. (1882), pág. 510.

40 ESCRIBANO MARTÍN, F.- Op Cit. (2001): Op. Cit. (2006), pág. 159.

41 RIVADENEYA, A.- Op. Cit. (1880), Tomo III, pág. 344.

42 OSSORIO Y BERNARD, M.- Galería biográfica de artistas españoles del siglo XIX. Imprenta de Moreno y Rojas, Madrid 1883-1884, pág. 521. PANTORBA, B. de.- Historia y crítica de las Exposiciones Nacionales de Bellas Artes celebradas en España. Jesús Ramón García-Rama J., Madrid 1980, págs. 98, 100, 108-109, 121 y 459. GONZÁLEZ, C. y MARTÍ, M.- Pintores españoles en Roma (1850-1900). Tusquets Editores, S. A., Barcelona 1987, pág. 153. REYERO, C., FREIXA, M.- Pintura y escultura en España, 1800-1910. Ediciones Cátedra, S. A., Madrid 1995, pág. 184. DIZY CASO, E.- Les orientalistes de l'école espagnole. ACR Édition Internationale, Courbevoie 1997, pág. 280. 
marchó a Roma, asistiendo a la Academia Chigi y entablando amistad con Mariano Fortuny y muchos otros pintores y artistas españoles que allí buscaban ampliar sus horizontes artísticos. A la influencia de Fortuny se debe sin duda algún cuadro de tono orientalista, como su lienzo Costumbres de Tánger ${ }^{43}$, pero es evidente que tanto por carácter como por el poso que le había dejado su trabajo y estudios previos junto a Martí Alsina, se sentía más próximo al realismo. De hecho, al volverse definitivamente a España en 1870, presentó a la Exposición Nacional de Bellas Artes de 1871 un cuadro pintado en Roma y titulado Zitto, silenzo che passa la ronda. Esta obra, que mereció una medalla y que como propiedad del museo de El Prado se conserva hoy en Barcelona, «revela su interés por hacer una pintura que fuera, sobre todo, crónica de la realidad» ${ }^{44}$. Por ello quizás en parte, desde este momento se volcó en la ilustración gráfica, terreno en el que podía desarrollar sus mejores cualidades de "dibujante, y aun más, de dibujante ilustrador» ${ }^{45}$, convirtiéndose al tiempo en un verdadero y valeroso corresponsal de guerra. Así lo vemos informando de la última Guerra Carlista (1872-1876) primero, como corresponsal de La Ilustración Española y Americana, y poco después de esta misma revista y de otras no españolas, documentando para los lectores europeos las incidencias de la tremenda Guerra Ruso-Turca de 1877-1878, adscrito al cuartel general del Gran Duque Nicolás de Rusia ${ }^{46}$. Sus dibujos bélicos ilustraban los hechos con tremendo realismo: la prestigiosa publicación española del siglo XIX guarda en sus páginas muchos de ellos, como los que recogen una ambulancia turca en el famoso sitio de Plevna, la vista de la ciudad de Schumla y apuntes tomados sobre soldados rusos ${ }^{47}$. J. L. Pellicer escribiría en la misma revista que "estos apuntes están impregnados de carácter»... «y desde luego les garantizo» ... que ... «son exactas reproducciones del natural» ... y que ... «los tipos militares rusos son también exactos». Es muy probable que en aquellas fechas conociera a otro pintor e ilustrador gráfico ruso, ya entonces célebre, Vasily Vereschaguin (1842-1904), también presente en Plevna y en todas las grandes batallas de aquella guerra. Un pintor que como él, más que orientalista en sentido estricto, como se le reputa con frecuencia, sería fiel narrador de cuanto viera en las campañas de los Balcanes, al igual que lo había sido ya en la conquista rusa de los últimos rincones de Asia Central ${ }^{48}$.

43 GONZALEZ, C. y MARTí, M.- Op. Cit. (1987), pág. 153.

44 REYERO, C. y FREIXA, M.- Op. Cit. (1995), pág. 184.

45 FONTBONA, F.- «La ilustración gráfica. Las técnicas fotomecánicas», en CARRETE, J. et alii.- El grabado en España (siglos XIX-XX). Espasa Calpe, S. A., Madrid 1988, Summa artis, vol. XXXII, 427607. Vid. pág. 442.

46 OSSORIO Y BERNARD, M.- Op. Cit. (1883-1884), pág. 521. PANTORBA, B. de.- Op. Cit. (1980), pág. 456.

47 La llustración Española y Americana, Año XXI, nํㅡXXXX, de 22 de octubre de 1877, págs. 252253. Las palabras de José Luis Pellicer se publican como fragmentos de su carta enviada a la redacción, en la nota de E. Martínez de Velasco «Crónica ilustrada de la Guerra de Oriente», que en la página 251 comenta las ilustraciones del corresponsal y los hechos de la guerra.

48 BAROOSHIAN, V. D.- V. V. Vereshchagin: Artist at War. University Press of Florida, Gainesville 1993. SCHIMMELPENNINCK VAN DER OYE, D.- «Vasilij V. Vereshchagin's Canvases of Central Asian Conquest», Cahiers d'Asie Centrale 17/18 (2009), págs. 179-209. KOUTEINIKOVA, I.- «Vasily Vereschagin's war and peace» en WAGEMAN, P. y KOUTEINIKOVA, I. (edas.).- Russia's unknow $n$ Orient. Groninger Museum, Groningen / Nai Publishers, Rotterdam 2011, págs. 86-131 
Rivadeneyra en Dizful. Notas sobre un óleo dedicado a la aventura...

Adolfo Rivadeneyra estaba pues en España a comienzos de 1876. En ese tiempo debió encargarle el cuadro deseado a José Luis Pellicer, quien lo firmaría a comienzos de 1877, puesto que el pintor se iría a la Guerra Ruso-Turca ese mismo año, y tras acabar el conflicto citado en 1878, al decir de M. Ossorio y Bernard presentó en la Exposición Nacional las siguientes obras: «Llegada a Dizful del Gobernador del Arabistán y del Loristán y del Vicecónsul de España, croquis remitidos por el expositor al periódico La Ilustración Española y Americana, como corresponsal del mismo en el ejército ruso (en siete cuadros), así como también varios dibujos y apuntes para un cuadro: fue premiado con medalla de tercera clase ${ }^{49}$. La contemplación de este lienzo de José Luis Pellicer debió llamar la atención del público, porque emana de él una vivacidad, un realismo y una atmósfera tan auténtica como poco habitual en la pintura orientalista al uso. Pero como describe una situación en Oriente, tal vez por ello quedó para muchos encuadrada en el género de la pintura de este signo, aunque en realidad fuera más propiamente un reportaje. El pintor siguió sin duda las indicaciones de Rivadeneyra, dado que su libro Viaje al interior de Persia, no vio la luz hasta algo después. Si cogemos el tomo II y buscamos las páginas correspondientes ${ }^{50}$ al episodio de Dizful, podremos casi seguir con los ojos los tipos y escenas descritos por el viajero: el medio uniforme del gobernador, la posición de Rivadeneyra con salacot, a caballo y a la izquierda de aquél, la variada escolta de caballería, las palmeras y las blancas casas de Dizful al fondo, las gentes de la ciudad arracimadas delante y en torno al cortejo, sacrificando cabritos, ovejas y vacas en honor del gobernador, el anciano vestido de blanco que alza la cabeza de vaca ante el gobernador, los derviches con gorros cónicos, la comisión de los descendientes del Profeta, con vestiduras y turbante de color verde ... En fin, nada dejado a la imaginación, nada sacrificado a la truculencia que algunos deseaban ver en los cuadros dedicados a Oriente. A decir verdad, la escena del cuadro está más cerca de los reportajes gráficos de Pellicer que de los cuadros que en la pintura orientalista europea y española, se convertían en «vía de escape, en ventana luminosa»... que ... «responde a un fuerte deseo de evasión»51.

Acabada la exposición, la obra volvió sin duda al domicilio madrileño de Adolfo Rivadeneyra, en cuyos muros debió iluminar sus recuerdos mientras redactaba las páginas del libro publicado en 1880. Así, en artículo dedicado a los pintores catalanes de entonces, escribía J. Güell y Mercader que «posee este hermoso cuadro el Sr. Rivadeneyra» ${ }^{52}$, para quien, como también decía, lo había pintado el artista catalán. José Luis Pellicer prosiguió su actividad artística en distintas exposiciones, organizó la Exposición Universal de Barcelona de 1888, fue director artístico de la editorial Montaner y Simón -llevando a cabo magníficas ilustraciones

49 OSSORIO Y BERNARD, M.- Op. Cit. (1883-1884), pág. 521. Según parece desprenderse de otra referencia de $\mathrm{B}$. de Pantorba, la medalla se la concedieron por los «croquis de la llustración Española y Americana». Véase PANTORBA, B. de.- Op. Cit. (1980), pág. 109.

50 RIVADENEYRA, A.- Op. Ct. (1880), Tomo II, págs. 24-247.

51 ARIAS ANGLÉS, E.- «La pintura orientalista», en A. E. Pérez Sánchez, A. Marí y E. Arias Anglés.- Pintura orientalista española (1830-1930). Fundación Banco Exterior, Madrid 1988, págs. 23-50. Vid. pág. 30 .

52 GÜELL Y MERCADER, J.- «Los pintores catalanes en nuestros días. IV», La llustración Española y Americana, Año XXI, noXXXIX, de 22 de octubre de 1877, pág. 362. 
de obras como El Quijote (1880-1883), La leyenda del Cid, de Zorrilla (1882), varios volúmenes de los Episodios Nacionales, de Galdós, como Gerona (1883) o El Grande Oriente (1884)-, entre muchas otras colaboraciones en numerosos libros y revistas ilustradas, y ostentó varias responsabilidades en la sociedad y la cultura barcelonesa, sin olvidar nunca su compromiso social ${ }^{53}$. Porque además de dibujante certero y maestro sabio, como decía de él Apeles Mestres, Pellicer fue autor de una obra que supuso un «documento de valor inconmensurable y creación estética de la máxima categoría» ${ }^{4}$. Y sin duda, aquel cuadro real como una foto y mágico como un sueño era un buen testimonio. Admirado y estimado, como artista y maestro de muchos, murió en Barcelona a mediados del año 1901. Para entonces, es muy posible que pocos recordaran ya que en paredes ministeriales colgaba un óleo único, testimonio veraz de dos españoles excepcionales.

Como se indica más arriba, muerto Adolfo Rivadeneyra el lienzo de José Luis Pellicer quedó en poder del estado. Y empezaron entonces los avatares de los que apenas si ahora acaba de salir. Del salón en el que «los ministros se reúnen en Consejo» 55 , donde según parece se encontraba el mismo año de su muerte, poco a poco la obra debió ser víctima de los caprichos decorativos de nuevos inquilinos, de las sucesivas modas artísticas y de oscuros traslados de departamento. Sólo así se entiende que se le perdiera el rastro, que se perdieran incluso los datos del inventario original —que supongo existirían-, y que un nuevo inventario, dejado en manos de alguien poco exigente, le asignara una entrada sorprendente: «Escena de Marruecos, óleo. Lienzo. 0,92 x 2,06 m. Ángulo inferior izquierdo: Pellicer / 1877. Madrid. Ministerio para las Administraciones Públicas». Y así embozado volvería a la luz, seleccionado para una exposición de pintura orientalista. Pero lo malo es que estos datos erróneos, y quizás la descripción de la obra que acompañaba la ficha correspondiente ${ }^{56}$ se difundieron con ocasión de la exposición citada, organizada por la Fundación Banco Exterior en Madrid, el año 1988. Se indicó entonces además que el cuadro representaba una escena de moros descuartizando unas reses, agrupados en torno a unos oficiales europeos, acompañados por askaris $(\operatorname{sic})^{57}$. La cosa no dejaba de tener cierta gracia, puesto que

53 FONTBONA, F.- Op. Cit. (1988), pág. 444. C. Reyero y M. Freixa recuerdan que era «un militante de izquierda e imbuido de las ideas que aspiraban a dotar el arte d e una misión social» ... y que "se opuso a la trivialidad preciosista». Así REYERO, C. y FREIXA, M.- Op.Cit. (1995), pág. 184.

54 FONTBONA, F.- Op. Cit. (1988), pág. 444.

55 SAAVEDRA, E.- Op. cit. (1882), pág. 510.

56 Recuerda E. Dizy que la ficha del ministerio, que catalogaba la obra como «Escena de Marruecos» decía lo siguiente: "La escena representa un campamento del Rif, Pueden distinguirse descansando a la hora en la que se preparar la comida. La escena viene completada por un grupo de jinetes armados» (!). Véase DIZY CASO, E.- Op. Cit. (1997), págn 280.

57 La verdad es que no puedo por menos que transcribir parte de la ficha publicada en el catálogo, que sin duda recoge los datos del inventario, y en la que con certeza nada tuvieron que ver los autores de los artículos publicados en el catálogo. El texto dice así: «esta escena multitudinaria, en la que se están descuartizando a unas reses por parte de un numeroso grupo de moros que se apiña en torno a unos oficiales europeos acompañados de «askaris», debe representar algún tipo de celebración local cuyo significado nos es desconocido. En la parte central, unos personajes vestidos de blanco y con gorros rojos saludan a los dos oficiales a caballo, levantando uno de ellos los cuernos de una res por encima de su cabeza». Véase PÉREZ SÁNCHEZ, A. E., MARÍ, A. y ARIAS ANGLÉS, E.- Op. Cit. 1988, pág. 108. 
Rivadeneyra en Dizful. Notas sobre un óleo dedicado a la aventura...

apenas un año antes, en su descripción paralela al viaje de Adolfo Rivadeneyra por Irán, Lily Litvak había publicado ${ }^{58}$ el grabado que sobre este cuadro hiciera José Luis Pellicer ${ }^{59}$, publicado a gran formato en un volumen de la revista barcelonesa La llustración Artística, pocos años después de la muerte de Rivaeneyra. Seguro que las personas más próximas a los estudios sobre el Oriente antiguo y la historia de la investigación debieron notar pronto el error, y lo que es mejor, se dieron cuenta también de lo positivo que encerraba el lance: que un cuadro singular y desaparecido acababa de volver a la luz. F. Fontbona lo subrayó pronto, como recoge Eduardo Dizy ${ }^{60}$ : yo mismo también, al ver la fotografía del cuadro publicada en el catálogo, pues recordaba la ilustración recién recogida por L. Litvak, y sin duda otros muchos colegas debieron percibir lo mismo. Por eso, recuperar la certeza de la imagen y la historia se convirtió en objetivo de algunos de los que nos dedicábamos ya entonces a estos asuntos. En obra a poco presentada en la Universidad Autónoma de Madrid, Fernando Escribano restituía las cosas a su punto cierto ${ }^{61}$, y no mucho después, él y yo mismo volvíamos a ver el original en un despacho del Ministerio de las Administraciones Públicas, cuando la Conservadora de Egipto y Oriente Próximo del Museo Arqueológico Nacional, Mª C. Pérez Díe y yo, como comisarios, preparábamos la selección de obras que tenían que integrar la exposición que el año 2006 iba a presentar en el museo madrileño, «La aventura española en Oriente (1166-2006). Viajeros, museos y estudiosos en la historia del redescubrimiento del Oriente Próximo Antiguo». Aquel cuadro de José Luis Pellicer Feñé se convertiría en el mejor símbolo e imagen de la exposición misma y de lo que ambos comisarios habíamos querido conseguir: «rescatar el olvido de los siglos»... «recuperar el recuerdo de las personas, los libros, las empresas de nuestros antepasados y transmitir el sabor de la aventura y la sorpresa y el temblor ante el haIlazgo» ${ }^{62}$.

\section{EPILOGO: RECUERDO PERENNE DE LOS PIONEROS}

Hace tiempo que el lienzo de José Luis Pellicer, «Llegada a Dizful del gobernador del Loristán y Arabistán y del vicecónsul de España», forma parte de nuestros recuerdos relacionados con la Historia y la Arqueología española y europea en Oriente Próximo. Así, la reciente edición de su Viaje al interior de Persia lo incluye

58 LITVAK, L.- Op. Cit. 1987, pág. 112.

59 Escribía A. Sánchez una nota titulada «El vice-cónsul Rivadeneyra en Dizful, cuadro de nuestro director artístico J. L. Pellicer»: en la página siguiente se incluían algunos apuntes sobre tipos de iraníes tomados por el pintor -vestidos y actuando según debió contarle el antiguo cónsul-, y mas adelante, el grabado del cuadro a gran formato. Véase La llustración Artística, Año V, no 235 de 28 de junio de 1886. La nota en pág. 226, los apuntes en la pág. 227, y el grabado del cuadro en pág. 235.

60 DIZY CASO, E.- Op. Cit. (1997), pág. 280. Cita el autor ahí un trabajo de F. Fontbona -publicado en la revista Awraq, de 1990-, recordando que éste decía que la supuesta «Escena de Marruecos» había sido encargo de Rivadeneyra, y que se podía seguir en su libro y en el relato de L. Litvak.

61 ESCRIBANO MARTÍN, F.- Op. Cit. 2001, pág. 112.

62 CÓRDOBA, J. Mª y PÉREZ DÍE, M ${ }^{a}$ C.- «La aventura española en Oriente (1166-2006)», en CÓRDOBA, J. Mª y PÉREZ DíE, Mํㅡㄹ C. (eds.).- Op. Cit. (2006), págs. 17-21. Vid. pág. 21. 
en su portada ${ }^{63}$. Y cuando el Museo Arqueológico Nacional reordene sus fondos dedicados a Mesopotamia e Irán, habrá de contar con ladrillos inscriptos que Adolfo Rivadeneyra trajo a España de sus viajes, con la intención de entregarlos al museo. Y aún más, cuando alguien quiera conocer la época de los pioneros en Oriente y los primeros hallazgos, leerá con gusto su Viaje de Ceilán a Damasco o su Viaje al interior de Persia. Pues Rivadeneyra es uno de los más señalados en el redescubrimiento de la Antigüedad oriental. Él quería dar a conocer a sus compatriotas las empresas de los viajeros pasados, la Historia remota de aquellas regiones, el presente que a cada paso se le abría. Él quería enseñar lo que formaba parte de su saber y su experiencia. Y consiguió hacerlo. Por eso siempre ya, su imagen y su recuerdo, lo mismo que el de nuestros maestros más cercanos, recibirá a quienes busquen en el Museo Arqueológico Nacional las raíces y el legado de la más remota Historia de la Humanidad. Un legado que él supo encontrar también entonces, en aquel instante supremo, en aquella luminosa mañana de Irán, cuando Adolfo Rivadeneyra cabalgaba hacia Dizful.

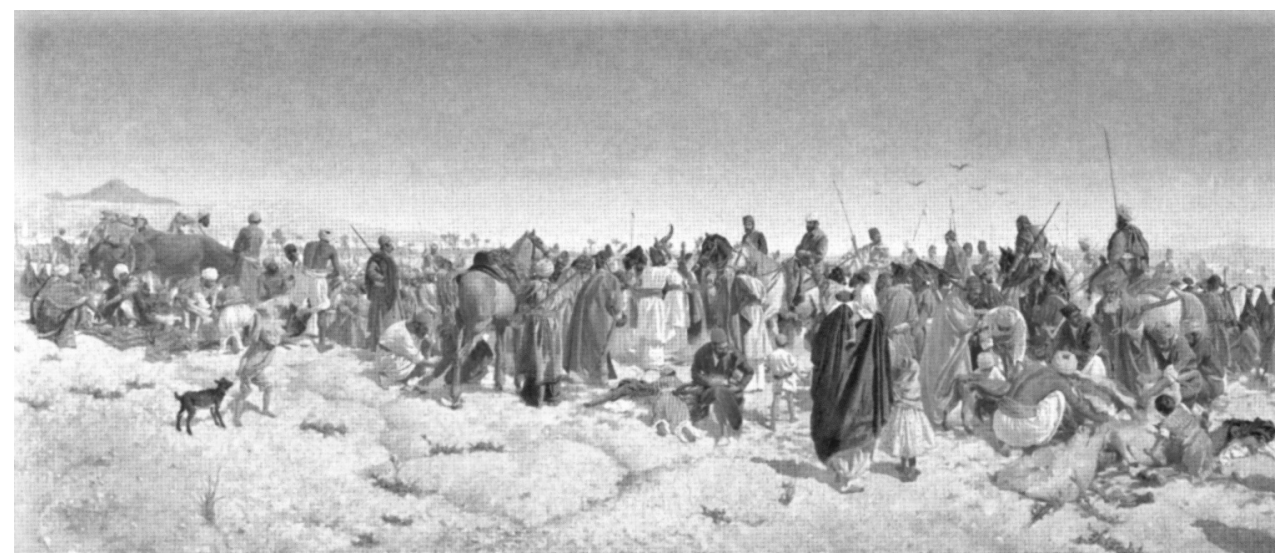

Fig. 1. Llegada a Dizful del gobernador del Loristán y Arabistán y del vicecónsul Rivadeneyra, óleo de J. L. Pellicer (según J, Mª Córdoba y M. C. Pérez Díe, eds., 2006, 207).

63 RIVADENEYRA, A.- Op. Cit. 2008, edición, prólogo y notas de Fernando Escribano, que en sus páginas 42 y 43 recuerda estos avatares. 
Rivadeneyra en Dizful. Notas sobre un óleo dedicado a la aventura...

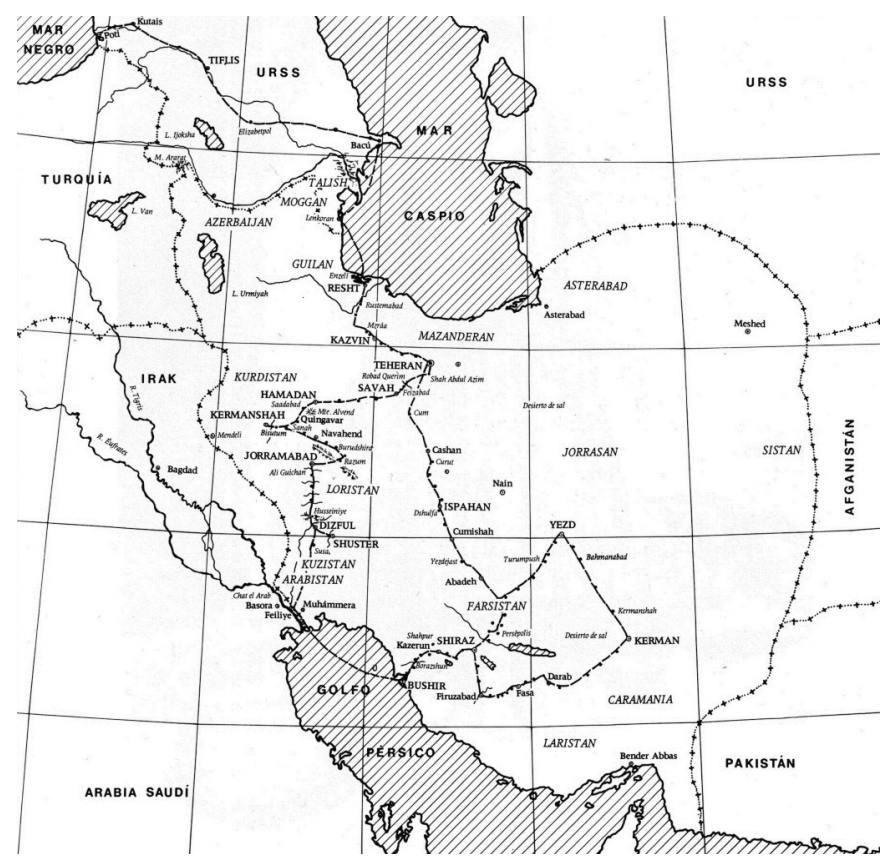

Fig. 2. Trayecto seguido por Adolfo Rivadeneyra en su viaje por el interior de Irán (según L. Litvak, 1987, 18).

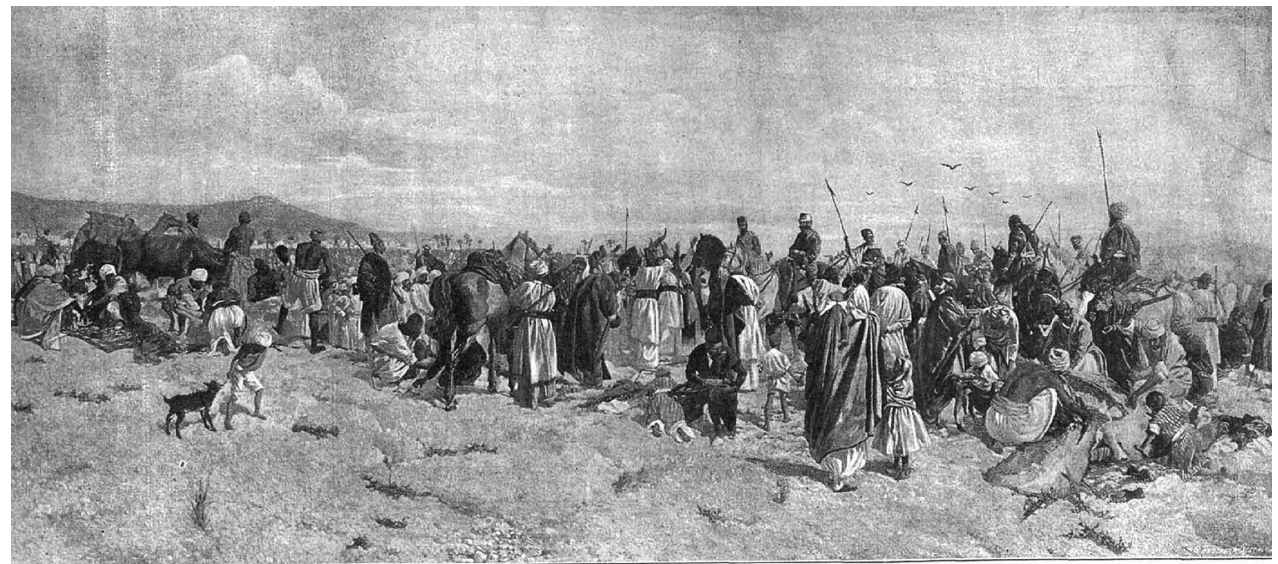

Fig. 3. Grabado de J. L. Pellicer, titulado «El vicecónsul Rivadeneyra en Dizful», publicado en La Ilustración Artística, año V, no 235, de 28 de junio de 1886, pág. 279. 
